\title{
Effect of the axial movement of misaligned journal on the performance of hydrodynamic lubrication journal bearing with rough surface
}

\author{
Biao $\mathrm{Li}^{1}$, Jun Sun ${ }^{2,}{ }^{*}$, Shaoyu Zhu ${ }^{2}$, Yangyang $\mathrm{Fu}^{2}$, Xiaoyong Zhao ${ }^{1}, \mathrm{Hu}$ Wang ${ }^{1}$, Qin Teng ${ }^{2}$, Yanping Ren ${ }^{3}$, \\ Yunqiang $\mathrm{Li}^{3}$, and Guixiang $\mathrm{Zhu}^{3}$ \\ ${ }^{1}$ School of Mechanical Engineering, Hefei University of Technology, Hefei, PR China \\ 2 School of Automotive and Transportation Engineering, Hefei University of Technology, Hefei, PR China \\ ${ }^{3}$ Weichai Power Co., Ltd, Weifang, PR China
}

Received: 17 December 2018 / Accepted: 26 March 2019

\begin{abstract}
Generally, the movement of journal along the direction of bearing axis under the combined action of various factors is neglected in the lubrication study of bearing, which is quite different from the actual working condition of bearing in the shaft-bearing system. In this paper, with a comprehensive consideration of the axial movement of journal, the surface topography of journal and bearing and the misalignment of journal, a new model about the hydrodynamic lubrication of misaligned journal bearing is established based on the average Reynolds equation. Considering the effect of the axial movement of misaligned journal, the lubrication characteristics parameters of rough journal bearing is presented and mainly discussed. The results show that the axial movement of misaligned journal has a distinct effect on the bearing lubrication characteristics. The influence of the axial movement of misaligned journal on the bearing lubrication characteristics is slightly reduced when considering the surface roughness.
\end{abstract}

Keywords: Journal bearing / misaligned journal / axial movement / surface topography / hydrodynamic lubrication

\section{Introduction}

The shaft-journal bearing system is one of the most important friction conjunctions in the mechanical devices, and is widely used in various types of transmission systems. The lubrication property of journal bearing directly affects the operational reliability of mechanical equipment. Many scholars have carried out a lot of research work on the lubrication property of journal bearings considering the journal misalignment and surface topography. Sun et al. [1-4] researched the influences of the misaligned journal, surface topography and elastic deformation on the lubrication performances of bearings, and measured the misalignment angle of journal and maximum oil film pressure on the specially designed test rig. They pointed out that the influence of the journal misalignment and surface topography must be considered in the design process of bearing, but the elastic deformation of bearing surface can be ignored. Then, the journal misalignment and surface morphology began to attract more and more

\footnotetext{
* e-mail: sunjun_hfut@163.com
}

attention, and many useful conclusions were obtained. Liu et al. [5-8] analyzed the influence of the misalignment of journal on the lubrication characteristics of bearings, and indicated that the misalignment of journal is one of factors that should be considered in the lubrication study of bearings. Zhen et al. [9] examined the effect of the misalignment of journal on the lubrication characteristics of bearing on the basis of considering the influence of the specific structure of stepped shaft on the inclination angle of shaft. Isaksson et al. [10] theoretically and experimentally investigated the influence of surface roughness on the tribological property of hybrid bearing, and pointed out that the theoretical simulation results are in agreement with the experimental values. Lv et al. [11-13] researched the influence of the surface slip and turbulence on the journal bearings performance based on the journal misalignment in the bearing bore. Rao et al. [14] investigated the effect of the surface configuration on the lubrication characteristics of journal bearing. They found that the bearing capacity is increased effectively and the friction coefficient of bearing is reduced by the surface porous layered structure of lubricating film. Li et al. [15] studied the effect of the distribution of surface roughness on 


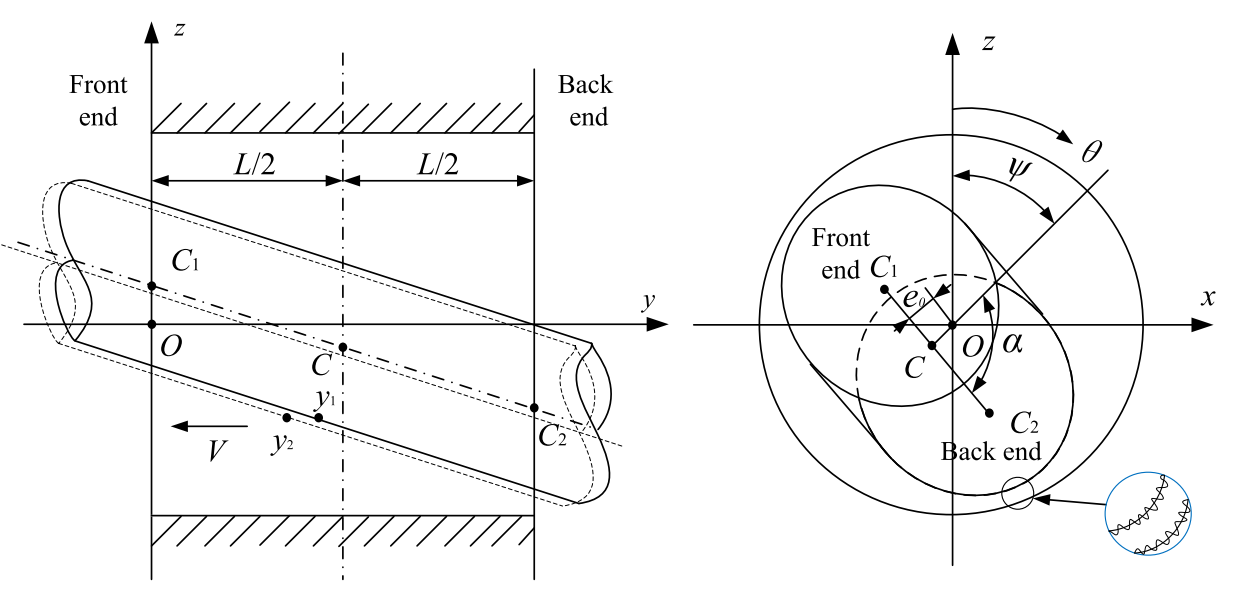

Fig. 1. The diagrammatic sketch of the axial movement of misaligned journal bearing.

the performance of slider bearings, and found that the influence of the skewness and kurtosis on the bearing performance should not be ignored. Wang et al. $[16,17]$ studied numerically the lubrication characteristics of textured bearings and non-textured bearings on the basis of the journal misalignment. None of the above studies had considered the axial movement of shaft. Generally, the researchers do not think that the shaft has a certain axial velocity along the bearing axis. Only the relative rotational movement and the relative squeezing movement between the journal surface and the bearing surface are usually considered in the lubrication study of journal bearing, the possible relative movement at the direction of bearing axis between the journal surface and the bearing surface is not considered. Gui et al. [18] used simulation method to study the movement of the crankshaft journal along the bearing axis. They pointed out that the shaft journal has a large displacement along the bearing axis. Then, Sun et al. [19] actually measured the trajectory of the journal center of crankshaft bearing on a specially test rig of a multi-cylinder engine, and pointed out that there is the axial velocity and displacement of crankshaft at the direction of bearing axial within a working cycle of engine and the axial displacement of crankshaft journal is far greater than the radial clearance of crankshaft main bearing. Han et al. [20,21] proposed a virtual-mesh approach to solve the difference equation of lubrication model in which the movement of shaft along the axial direction of shaft is considered. However, the effect of the shaft axial motion on the oil film thickness at radial direction of bearing is not considered and there are some errors in the established lubrication model by using axial velocity of shaft along the journal axis.

In actual operation, the journal bearing is mainly used as the support in the shaft-bearing system, and the journal of bearing is belong to a part of the shaft. The axial movement of the shaft in the shaft-bearing system caused by various factors (the axial force, deformation and impact, etc.) is unavoidable, which will result in the axial movement of journal and has direct effect on the lubrication characteristics of journal bearing. In this paper, the shaft-journal bearing system is taken as the research object, based on the average Reynolds equation, a lubrication model of rough journal bearing considering the axial movement of misaligned journal is established. The influence rule of the axial movement of misaligned journal on the load-carrying capacity, oil film pressure, side leakage flow, frictional power loss and overturning moment of journal bearing with rough surface are presented and analyzed.

\section{Modeling}

\subsection{Oil film thickness}

As shown in Figure 1, when the journal is tilted in the bearing hole, the axial movement of misaligned journal at the direction of bearing axis will directly change the oil film thickness distribution in the axial section of bearing, thereby impacts the oil film thickness distribution in the radial section of bearing. When the misaligned journal moves to the left along the bearing axis, the point $y_{1}$ on the misaligned journal surface moves to $y_{2}$, then the oil film thickness distribution in the cross section of bearing at $y_{2}$ is the same as that in the cross section of the bearing at $y_{1}$. Thus, the oil film thickness at $y_{2}$ can be expressed by the oil film thickness at $y_{1}$ before the axial movement of journal. The oil film thickness equation [22] considering the axial movement of misaligned journal is then written as:

$$
\begin{gathered}
h=c+e_{0} \cos (\theta-\psi)+\tan \gamma\left(y+V \cdot \Delta t-\frac{L}{2}\right) \\
\cos (\theta-\alpha-\psi),
\end{gathered}
$$

where $e_{0}$ is the eccentricity at the axial mid-section of bearing, $\psi$ is attitude angle at the axial mid-section, $\alpha$ is the angle between $\psi$ and the connecting line between the center of journal, $c$ is the clearance of bearing, $\gamma$ is the misalignment angle of journal, $\theta$ is the circumferential angle, $\Delta t$ is the time required for the journal to rotate an unit angle, $L$ is the bearing width, $y$ is the axial coordinate, $V$ is the velocity of journal at the direction of bearing axis.

\subsection{Reynolds equation}

Considering the axial velocity of misaligned journal, the radial component caused by the axial displacement and the impact of the surface topography of journal and bearing, 
the average Reynolds equation [22] used for the lubrication study of misaligned journal bearing can be expressed as:

$$
\begin{aligned}
& \frac{\partial}{\partial \theta}\left(\phi_{x} h^{3} \frac{\partial p}{\partial \theta}\right)+R^{2} \frac{\partial}{\partial y}\left(\phi_{y} h^{3} \frac{\partial p}{\partial y}\right) \\
& \quad=6 \eta U R \frac{\partial h_{T}}{\partial \theta}+6 \eta V R^{2} \frac{\partial h_{T}}{\partial y}+6 \sigma \eta U R \frac{\partial \phi_{s}}{\partial \theta} \\
& \quad+6 \sigma \eta V R^{2} \frac{\partial \phi_{s}}{\partial y}+12 R^{2} \eta \frac{\partial h_{T}}{\partial t}
\end{aligned}
$$

where $p$ is the oil film pressure, $U$ is the velocity of journal surface at the circumferential direction, and $U=\pi R n / 30$, $n$ is the rotational speed of journal, $R$ is the bearing radius, $\eta$ is the dynamic viscosity of lubricant, $\sigma$ is the composite rms roughness, $\sigma=\sqrt{\sigma_{1}^{2}+\sigma_{2}^{2}}, \phi_{x}, \phi_{y}$ and $\phi_{s}$ are the pressure and shear flow factors defined in references [22,23], $h_{T}$ is the local film thickness.

$$
h_{T}=\frac{h}{2}\left[1+\operatorname{erf}\left(\frac{h}{\sqrt{2} \sigma}\right)\right]+\frac{\sigma}{\sqrt{2} \pi} \exp \left(-h^{2} / 2 \sigma^{2}\right),
$$

where $\operatorname{erf}()$ is the error function to express the average clearance between two rough surfaces more accurately [24].

\subsection{Load-carrying capacity}

The two components of load-carrying capacity at $x$ and $z$ coordinates can be calculated by [1]:

$$
\begin{aligned}
& F_{x}=-\int_{0}^{L 2 \pi} \int_{0}^{2 \pi} p R \sin \theta d \theta d y, \\
& F_{z}=-\int_{0}^{L 2 \pi} \int_{0}^{2 \pi} p R \cos \theta d \theta d y .
\end{aligned}
$$

The load $F$ is then can be expressed as follows:

$$
F=\sqrt{F_{x}^{2}+F_{z}^{2}}
$$

\subsection{Side leakage flow}

Considering the axial movement of journal and the surface topography of journal and bearing, the flow and distribution of lubricant between the surfaces of bearing and journal will change significantly, which will affect the leakage flow of lubricant at the bearing end. The calculation formula of the side leakage flow of lubricant from the front and rear end planes of bearing are given by $[22,23]$ :

$$
\begin{aligned}
Q_{1} & =\int_{0}^{2 \pi}\left(\frac{V h_{T}}{2}+\frac{V \sigma}{2} \phi_{s}-\left.\phi_{y} \frac{h^{3}}{12 \eta} \frac{\partial p}{\partial y}\right|_{y=0}\right) R d \theta \\
Q_{2} & =\int_{0}^{2 \pi}\left(\frac{V h_{T}}{2}+\frac{V \sigma}{2} \phi_{s}-\left.\phi_{y} \frac{h^{3}}{12 \eta} \frac{\partial p}{\partial y}\right|_{y=L}\right) R d \theta
\end{aligned}
$$

The total side leakage flow can be expressed as follows:

$$
Q=\left|Q_{1}\right|+\left|Q_{2}\right|
$$

\subsection{Friction power loss}

When considering the effect of the axial movement of misaligned journal and the surface topography of journal and bearing, the friction force caused by the circumferential movement [3] and axial movement [25] of journal are defined as:

$$
\begin{aligned}
& F_{U}=\int_{0}^{L} \int_{0}^{2 \pi}\left(\frac{h}{2} \frac{\partial p}{R \partial \theta} \phi_{f p}+\frac{U \eta}{h}\left(\phi_{f}+\phi_{f s}\right)\right) R d \theta d y \\
& F_{V}=\int_{0}^{L} \int_{0}^{2 \pi}\left(\frac{h}{2} \frac{\partial p}{\partial y} \phi_{f p}+\frac{V \eta}{h}\left(\phi_{f}+\phi_{f s}\right)\right) R d \theta d y
\end{aligned}
$$

where $\phi_{f p}, \phi_{f}, \phi_{f s}$ are the shear stress factors defined in references $[22,23]$.

The total friction power loss is supposed to be the sum of the liquid friction power loss arising from the circumferential movement and axial movement of journal, which can be expressed as:

$$
P_{j}=F_{U} \cdot U+F_{V} \cdot V .
$$

\subsection{Overturning moment}

The components of overturning moment at $x$ and $z$ coordinates can be expressed as follows [1]:

$$
M_{x}=\int_{0}^{L} \int_{0}^{2 \pi} p\left(y-\frac{L}{2}\right) R \cos \theta d \theta d y
$$

$$
M_{z}=\int_{0}^{L} \int_{0}^{2 \pi} p\left(y-\frac{L}{2}\right) R \sin \theta d \theta d y
$$

The total overturning moment can be calculated as follows:

$$
M=\sqrt{M_{x}^{2}+M_{z}^{2}}
$$

\subsection{Convergence criterion}

The iterative procedure for solving the Reynolds equation is terminated when the following convergence criterion can be satisfied.

$$
\frac{\sum_{i=1}^{m} \sum_{j=1}^{n}\left|p_{i, j}^{(k+1)}-p_{i, j}^{(k)}\right|}{\sum_{i=1}^{m} \sum_{j=1}^{n} p_{i, j}^{(k+1)}} \leq 10^{-6},
$$




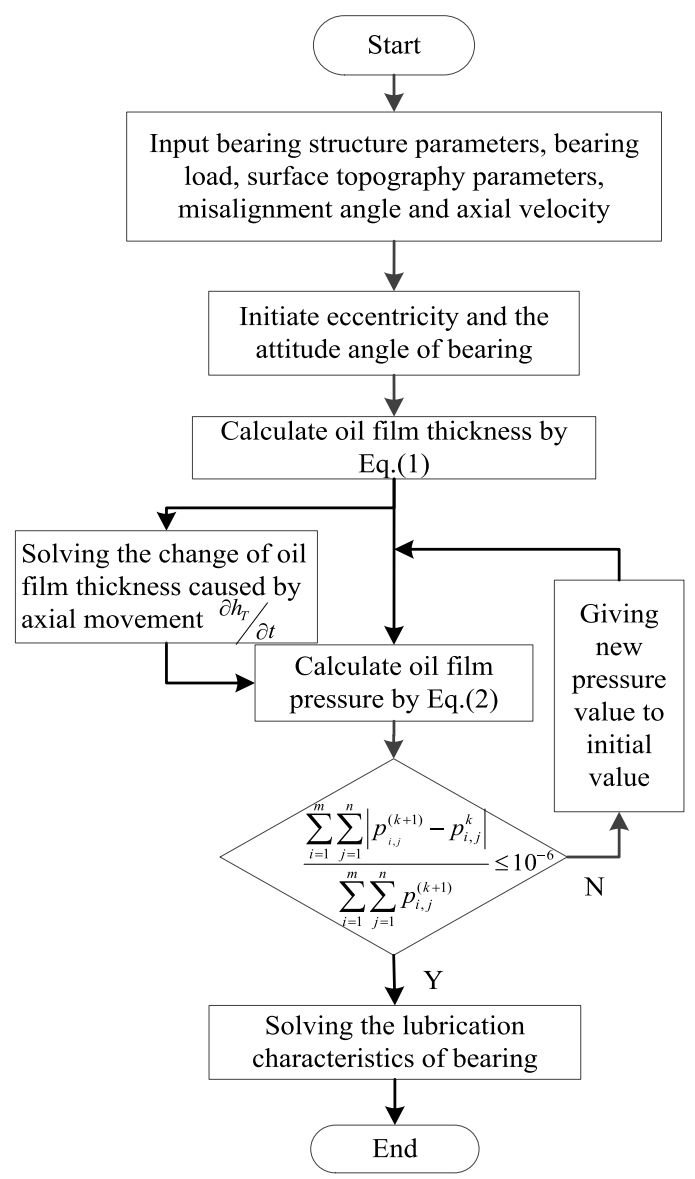

Fig. 2. Flow chart of numerical solution.

where $k$ is the number of iteration, $m$ and $n$ are the numbers of grids at the circumferential and axial direction of bearing respectively and $m=288, n=135, p_{i, j}$ is the film pressure at node $(i, j)$.

\section{Numerical solving method and validation}

\subsection{Numerical solving method}

Based on the Reynolds boundary conditions, the finite difference method is used to solve the differential equation of the lubrication equation (2). The super-relaxation iteration method is used to calculate the discrete equation of film pressure, and the Simpson integral method is used to solve the lubrication characteristic parameters of journal bearing. According to the axial velocity and displacement of journal, the surface topography parameters, the structural parameters of bearing and the positional parameters of journal in bearing hole, the oil film thickness of each node is calculated by the formula (1). The lubrication equation is solved based on the convergence criterion (15) to obtain the oil film pressure distribution of each node of bearing. Finally, the lubrication characteristic parameters of journal bearing are calculated according to the formulas (3)-(14). The diagrammatic sketch of the numerical solution process is shown in Figure 2.
In order to accelerate the iterative convergence and ensure the accuracy of the calculation results, the oil filmsolving domain is divided into 38880 parts, which are divided into 288 nodes in the circumferential direction and 135 nodes in the axial direction.

\subsection{Validation}

Figure 3 shows the comparison between the maximum oil film pressure and load-carrying capacity of bearing (whose main parameters are listed in Tab. 1) obtained by the present model and calculated in the references [1] and [11]. It shows that the maximum film pressure and load-carrying capacity calculated by the lubrication model of this paper is basically consistent with the results in the references [1] and [11], which proves the correctness of the main model and algorithm used in this paper, and the accuracy of the analysis results.

\section{Results and discussions}

The effect of the axial movement of misaligned journal on the performances of journal bearing with rough surface is analyzed. The main parameters of journal bearing are listed in Table 2.

\subsection{Influence of journal misalignment}

Figure 4 shows the variation of the lubrication characteristic parameters of bearing (the maximum oil film pressure $p_{\text {max }}$, load-carrying capacity $F$, side leakage flow $Q$, friction power loss $P_{j}$ and overturning moment $M$ ) versus the axial velocity of journal for three different misalignment angles whether or not consider the influence of surface roughness $\left(\sigma_{1}=0.4, \sigma_{2}=0.8\right)$. It is noticed from Figure 4 when the misalignment angle of journal is zero, the axial movement of journal has no effect on the lubrication characteristics (except for the $Q$ and $P_{j}$ ) of bearing whether or not the influence of the surface roughness is considered. The main reason for this phenomenon is that the axial movement of journal causes the oil film to have a certain axial velocity, which directly leads to the significant increase of the $Q$ and $P_{j}$. When the misalignment angle of journal is greater than zero, the values of $p_{\max }, F, Q, P_{j}$ and $M$ all increase with an increase of the axial velocity of journal, and the larger the misalignment angle, the more significant the increase. The main reason for those phenomenon may be that the larger the misalignment angle, the smaller the minimum oil film thickness of bearing, and the more obvious the hydrodynamic effect caused by the axial movement of misaligned journal. With the increase of the axial velocity of misaligned journal, the influence of surface roughness on the lubrication characteristics $\left(p_{\max }, F\right.$, and $M$ ) of bearing decreases gradually, while an opposite effect on $P_{j}$ will be. This may be attributed to the fact that when the position of misaligned journal in bearing hole is fixed, the impact of surface roughness on the lubrication characteristics of bearing is constant. As the axial velocity of misaligned journal increases, the maximum oil film pressure and loadcarrying capacity increase significantly, and the effect of 


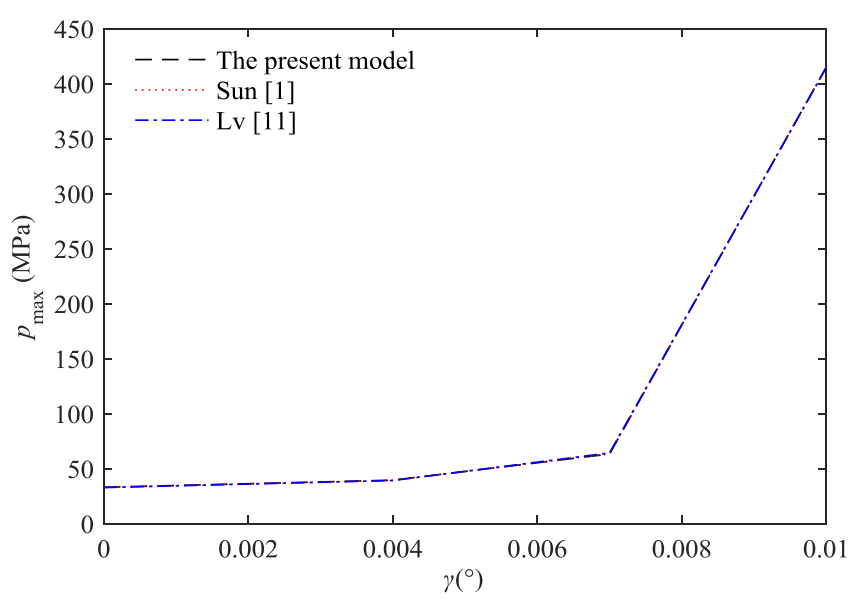

(a) Maximum film pressures $(\varepsilon=0.8)$

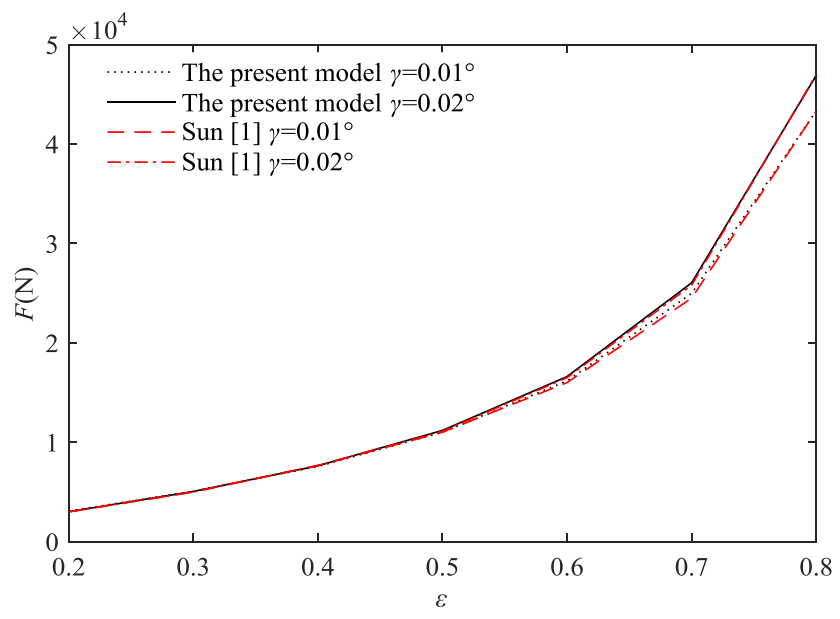

(b) Load-carrying capacity

Fig. 3. The maximum film pressures and load-carrying capacity: (a) maximum film pressures $(\varepsilon=0.8)$; (b) load-carrying capacity.

Table 1. Main parameters of journal bearing.

\begin{tabular}{lll}
\hline Parameters & Symbol & Numerical value \\
\hline $\begin{array}{l}\text { Rotation speed of bearing } \\
\text { rpm) }\end{array}$ & $n$ & 3000 \\
Bearing radius $(\mathrm{mm})$ & $R$ & 30 \\
Bearing width $(\mathrm{mm})$ & $L$ & 66 \\
$\begin{array}{l}\text { Radius clearance }(\mathrm{mm}) \\
\text { Viscosity of lubricant }\end{array}$ & $c$ & 0.03 \\
$(\mathrm{~Pa} \cdot \mathrm{s})$ & $\eta$ & 0.009 \\
Journal misalignment & $\gamma$ & $0.004 \sim 0.02$ \\
angle $\left(^{\circ}\right)$ & & $0.2 \sim 0.8$ \\
Eccentricity & $\varepsilon$ &
\end{tabular}

surface roughness on the maximum oil film pressure and load-carrying capacity decreases. The axial velocity of misaligned journal makes the friction power loss of bearing increase more significantly when the surface roughness is considered. Comparing with not considering the axial movement of misaligned journal, the maximum oil film pressure and friction power loss of bearing are increased by 25.07 and $3.13 \%$ respectively when the axial velocity is $1 \mathrm{~m} / \mathrm{s}$ (the misalignment angle is $0.007^{\circ}$ ) for not considering the surface roughness. When considering the influence of surface roughness, the maximum oil film pressure and friction power loss of journal bearing are increased by 16.89 and $4.39 \%$, respectively.

\subsection{Influence of rotational speed of bearing}

Figure 5 shows the variation of the lubrication characteristic parameters of bearing versus the axial velocity of journal for three different rotational speeds of journal whether or not consider the influence of surface roughness $\left(\sigma_{1}=0.4, \sigma_{2}=0.8\right)$. It can be seen that the value of the
Table 2. Main parameters of journal bearing.

\begin{tabular}{|c|c|c|}
\hline Parameters & Symbol & Numerical value \\
\hline $\begin{array}{l}\text { Rotation speed of bearing } \\
(\mathrm{rpm})\end{array}$ & $n$ & $1500 \sim 4000$ \\
\hline Bearing radius (mm) & $R$ & 30 \\
\hline Bearing width $(\mathrm{mm})$ & $L$ & 66 \\
\hline Radius clearance (mm) & $c$ & 0.03 \\
\hline Viscosity of lubricant $(\mathrm{Pa} \cdot \mathrm{s})$ & $\eta$ & 0.009 \\
\hline Journal misalignment angle $\left(^{\circ}\right)$ & $\gamma$ & $0.004 \sim 0.007$ \\
\hline Axial velocity $(\mathrm{m} / \mathrm{s})$ & $V$ & $0 \sim 1$ \\
\hline $\begin{array}{l}\text { Surface roughness of journal } \\
(\mu \mathrm{m})\end{array}$ & $\sigma_{1}$ & $0.2,0.4$ \\
\hline $\begin{array}{l}\text { Surface roughness of bearing } \\
(\mu \mathrm{m})\end{array}$ & $\sigma_{2}$ & $0.4,0.8$ \\
\hline Surface direction parameter & $\gamma_{0}$ & $1 / 9 \sim 9$ \\
\hline
\end{tabular}

lubrication characteristic parameters of bearing get increase with the increase in the axial velocity of journal for a constant value of the rotational speed of journal, and the lower the rotational speed, the more significant the increase. This may be attributed to the fact that the lower the rotational speed, the relatively larger the axial velocity of misaligned journal, the greater the hydrodynamic effect formed by the axial velocity, and the more obvious the influence. Comparing by, the influence of the surface roughness of journal and bearing on the maximum oil film pressure, load-carrying capacity and overturning moment decreases in varying degrees with the increase of the axial velocity of misaligned journal. The lower the rotational speed and the relatively smaller the axial velocity of misaligned journal, the more obvious the influence of surface roughness. The main reason for this phenomenon is that when the rotational speed and eccentricity of journal are constant, the greater the axial 


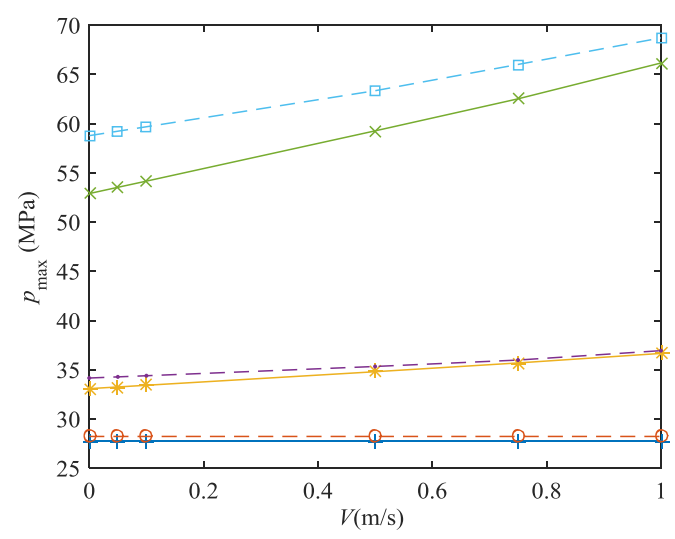

(a) Maximum oil film pressure

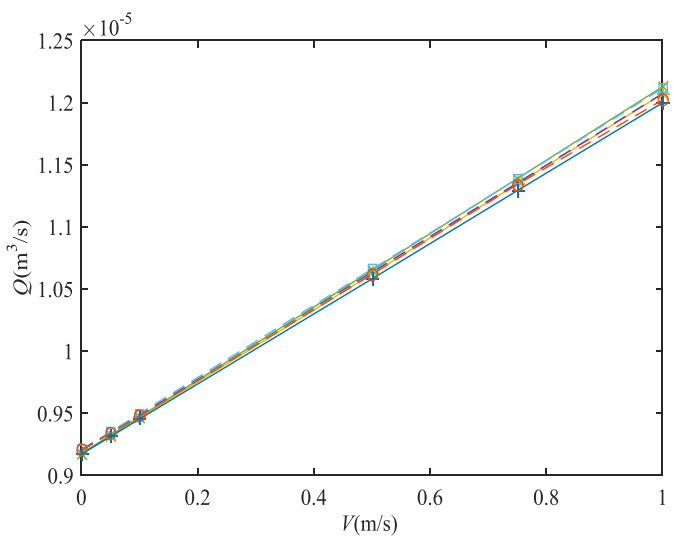

(c) Side leakage flow

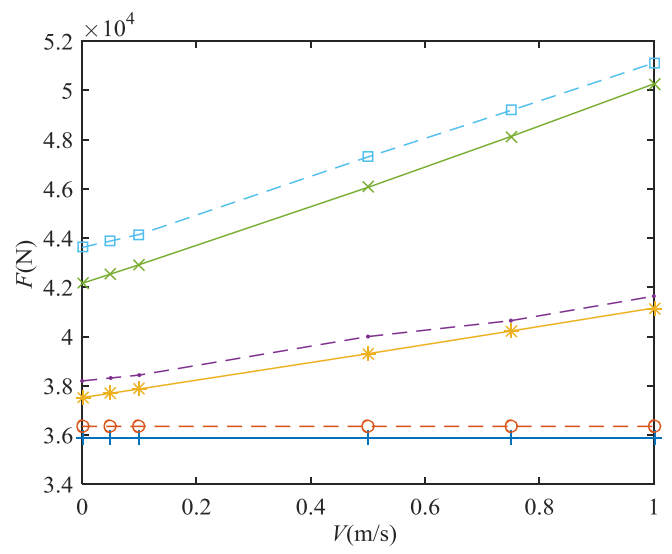

(b) Load-carrying capacity

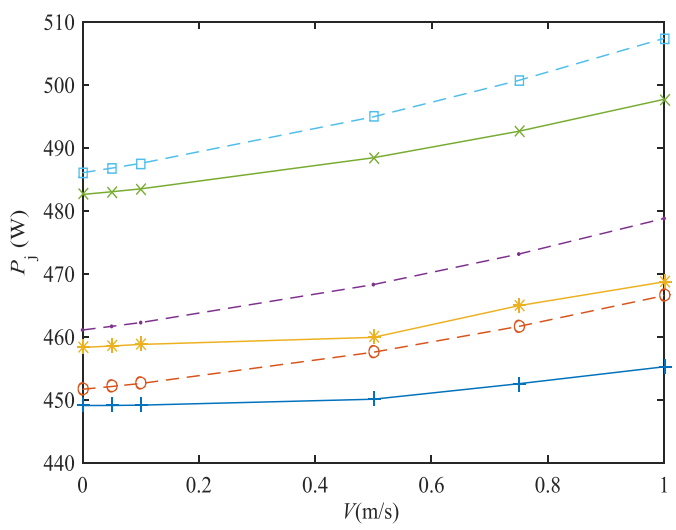

(d) Friction power loss
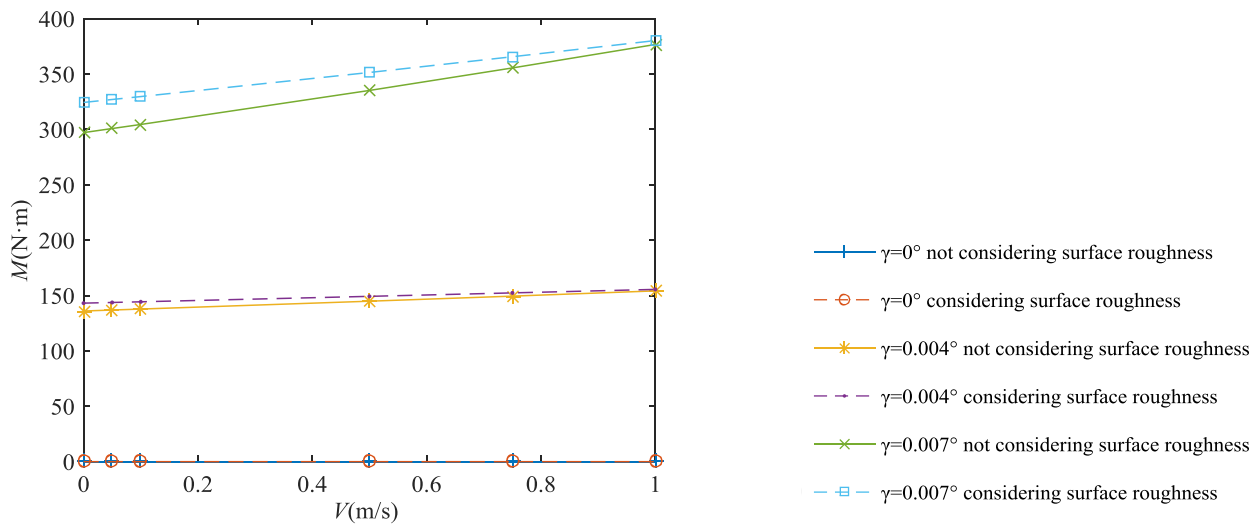

(e) Overturning moment

Fig. 4. The lubricating characteristics of bearing versus the axial velocity of journal for three different misalignment angles whether or not consider the influence of surface roughness $\left(n=2500 \mathrm{rpm} ; \varepsilon=0.8 ; \gamma_{0}=1\right)$ : (a) maximum oil film pressure; (b) load-carrying capacity; (c) side leakage flow; (d) friction power loss; (e) overturning moment.

velocity of misaligned journal, the larger the value of the lubrication characteristics of bearing caused by the axial movement of misaligned journal, thus the influence degree of surface roughness will be reduced. Comparing with not considering the axial movement of journal, the maximum oil film pressure is increased by $12.77 \%$ when the axial velocity is $1 \mathrm{~m} / \mathrm{s}$ (the rotational speed is
$4000 \mathrm{rpm}$ ) for not considering the surface roughness, but the increase of maximum oil film pressure is $10.03 \%$ when considering the influence of surface roughness. It can be seen from the results that when considering the impact of surface roughness, the influence of the axial movement of misaligned journal on maximum oil film pressure of bearing is slightly reduced. 


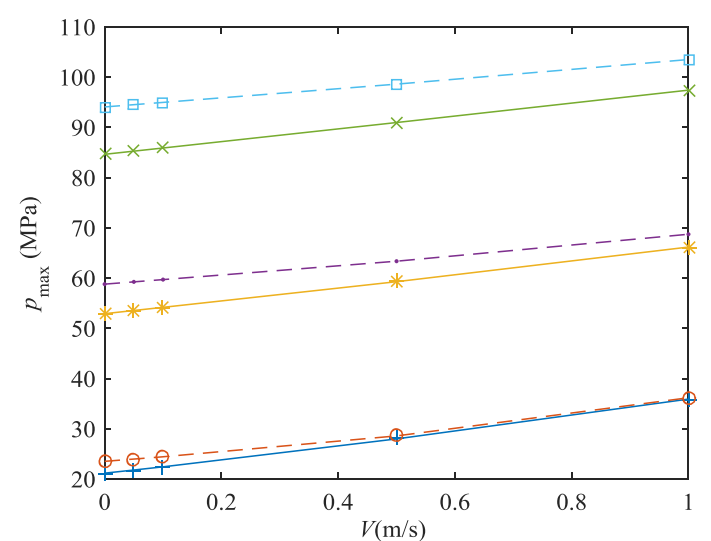

(a) Maximum oil film pressure

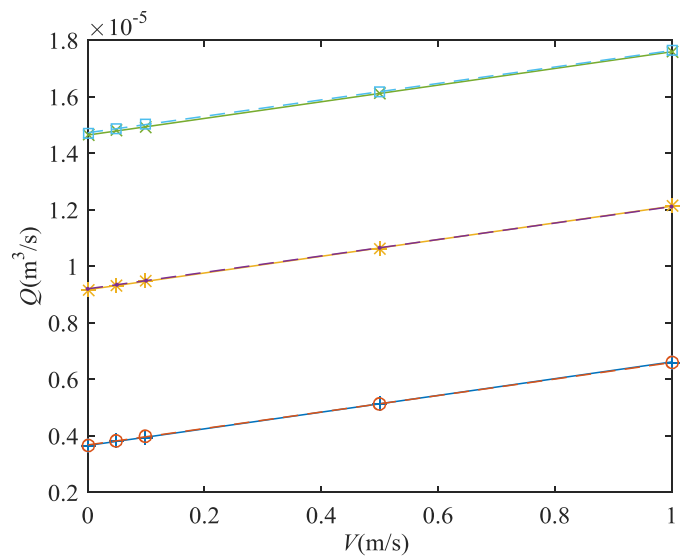

(c) Side leakage flow

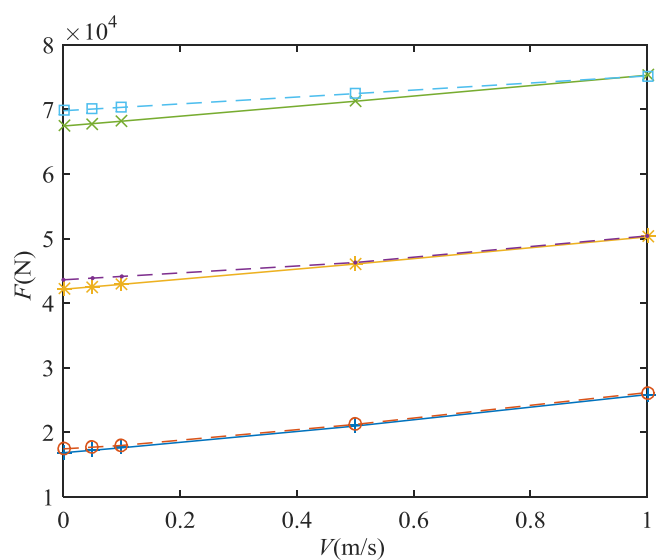

(b) Load-carrying capacity

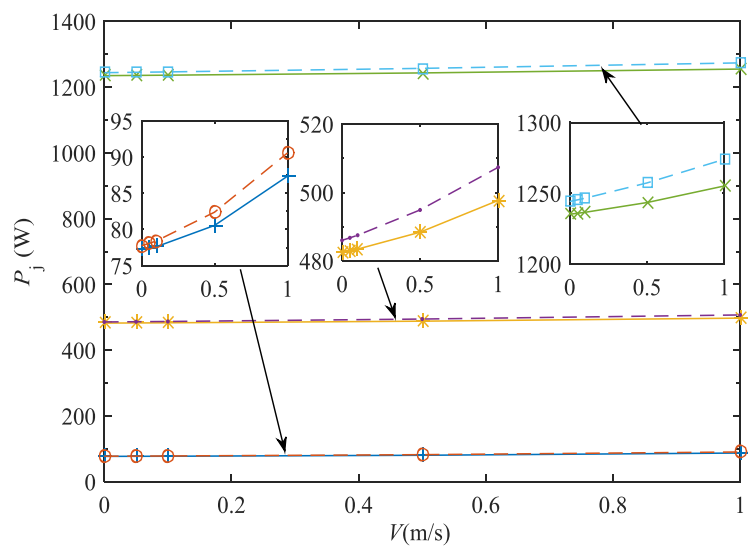

(d) Friction power loss
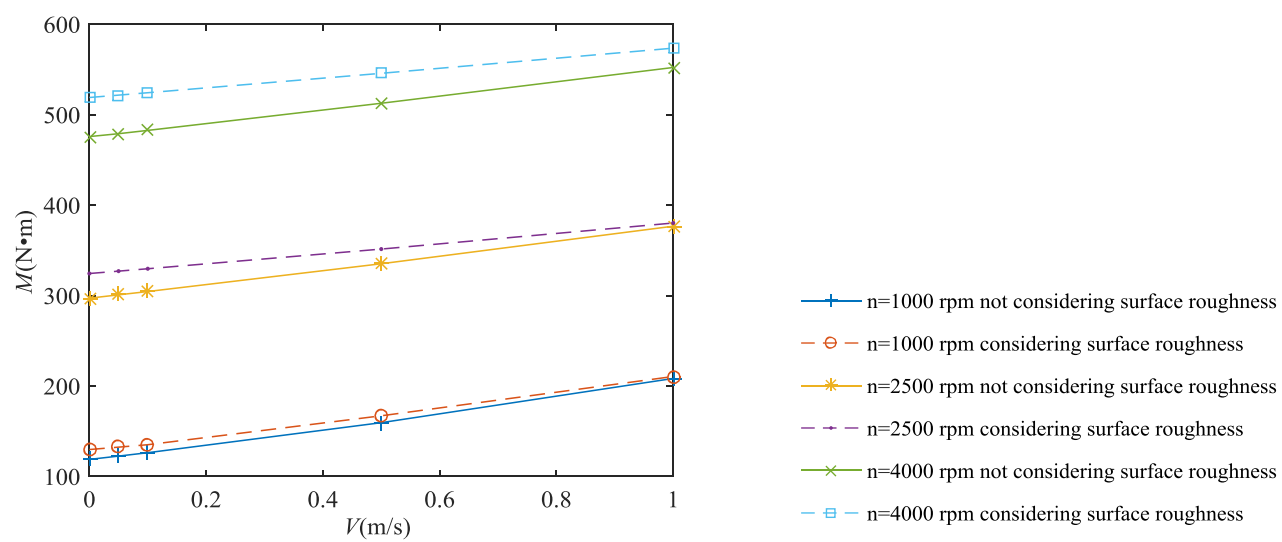

(e) Overturning moment

Fig. 5. The lubricating characteristics of bearing against the axial velocity of journal under different rotation speed when considering and not considering the surface roughness $\left(\gamma=0.007^{\circ} ; \varepsilon=0.8 ; \gamma_{0}=1\right)$ : (a) maximum oil film pressure; (b) load-carrying capacity; (c) side leakage flow; (d) friction power loss; (e) overturning moment.

\subsection{Influence of bearing eccentricity}

Figure 6 shows the variation of the lubrication characteristic parameters of bearing versus the eccentricity of bearing for three different axial velocity of journal whether or not consider the influence of surface roughness $\left(\sigma_{1}=0.4, \sigma_{2}=0.8\right)$. Obviously, it can be seen from the Figure 6 that when the axial velocity of misaligned journal is constant, the value of the lubrication characteristic parameters of bearing all increase significantly with an increase of eccentricity whether or not consider the influence of surface roughness. When the eccentricity is constant, the greater the axial velocity of misaligned journal, the greater the increase of the value of the lubrication characteristic parameters of bearing, and the 


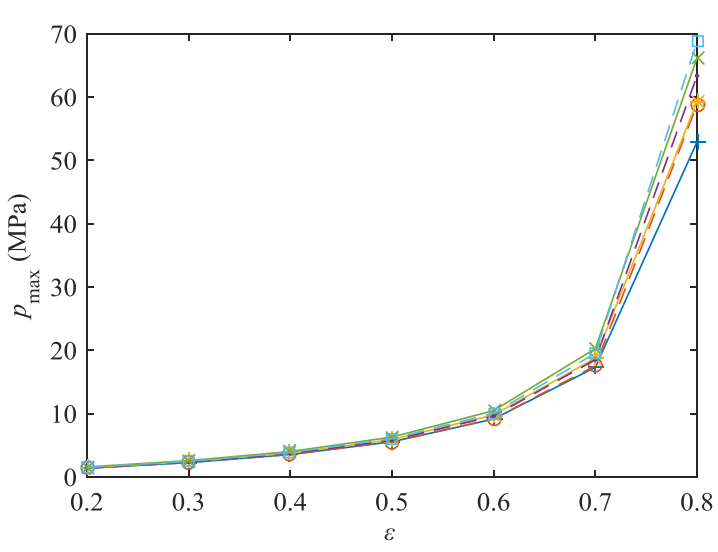

(a) Maximum oil film pressure

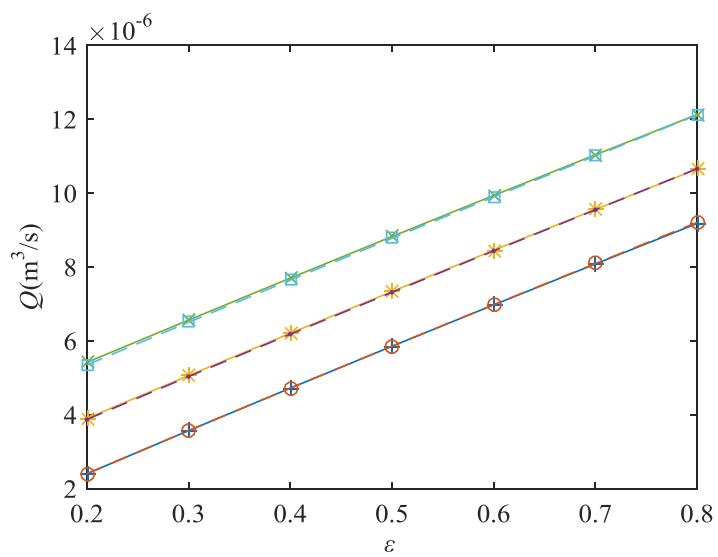

(c) Side leakage flow

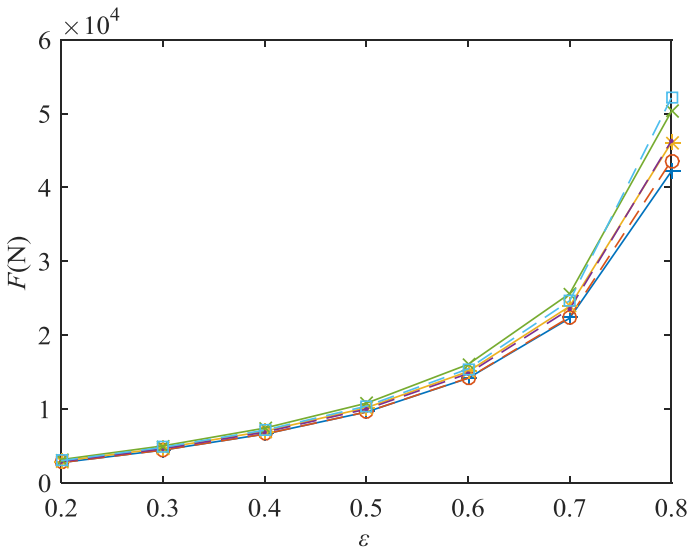

(b) Load-carrying capacity

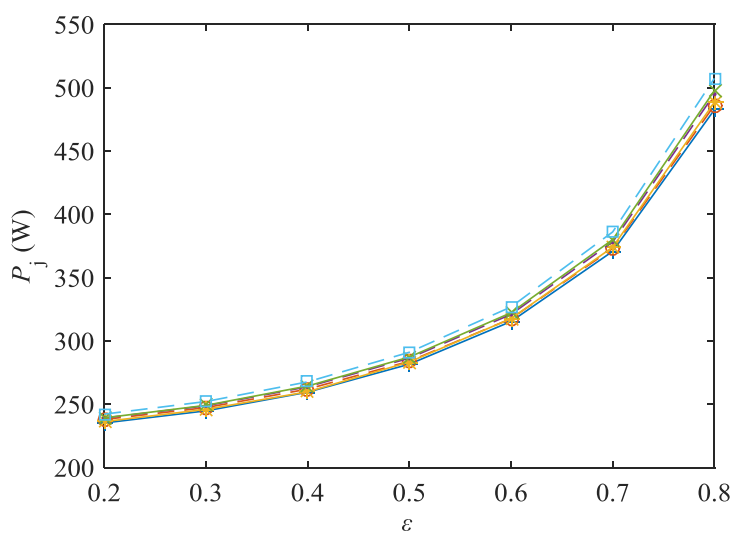

(d) Friction power loss
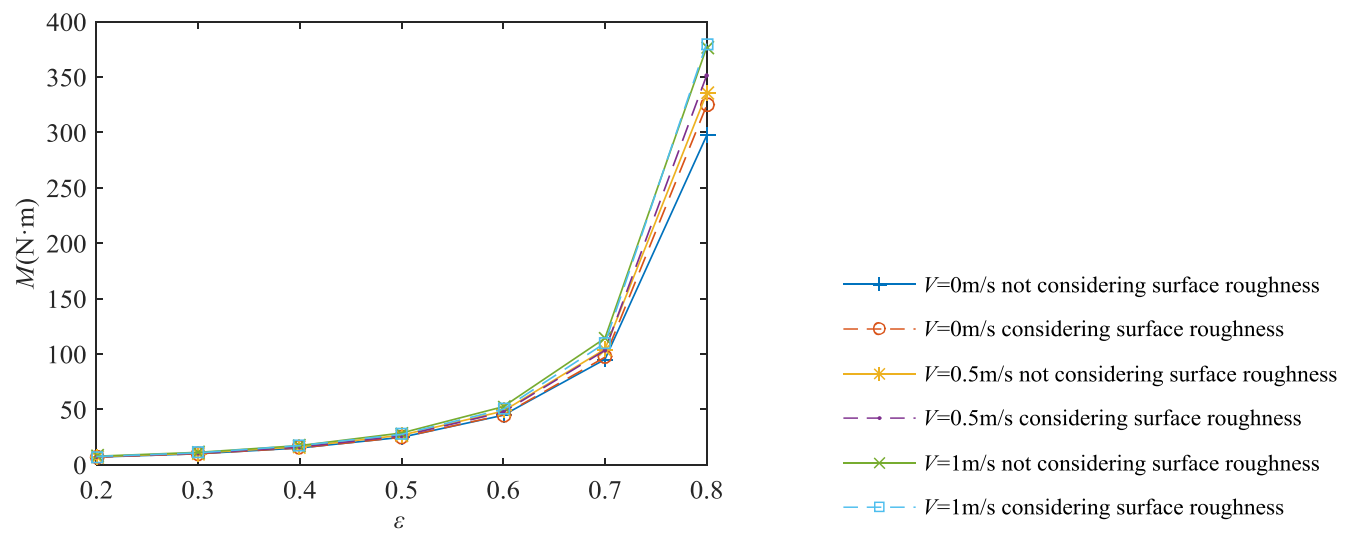

(e) Overturning moment

Fig. 6. The lubricating characteristics of bearing against the eccentricity under different axial velocity when considering and not considering the surface roughness $\left(\gamma=0.007^{\circ} ; n=2500 \mathrm{rpm} ; \gamma_{0}=1\right)$ : (a) maximum oil film pressure; (b) load-carrying capacity; (c) side leakage flow; (d) friction power loss; (e) overturning moment.

bigger the eccentricity, the greater the degree of increase. The main reason maybe is that the bigger the eccentricity, the smaller the minimum value of oil film thickness, and the greater the influence of the axial movement of misaligned journal on the oil film thickness. Compared with not considering the influence of surface roughness, the influence of the surface roughness on the maximum oil film pressure, load-carrying capacity and overturning moment of bearing is smaller as the axial velocity of journal misalignment increases when the eccentricity is constant. For not considering the effect of surface roughness, when the value of eccentricity is 0.8 and the axial velocity of journal is $0,0.5$ and $1 \mathrm{~m} / \mathrm{s}$, respectively, the maximum oil film pressure is 52.90,59.27 and 66.16 MPa, respectively. But the maximum oil film pressure 


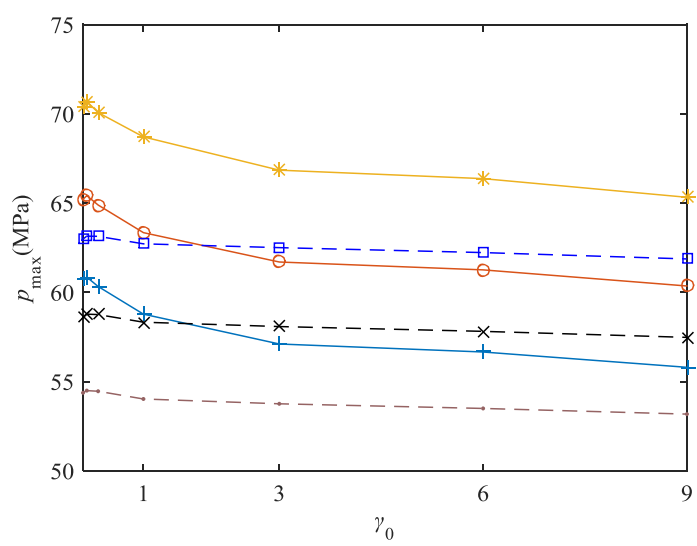

(a) Maximum oil film pressure

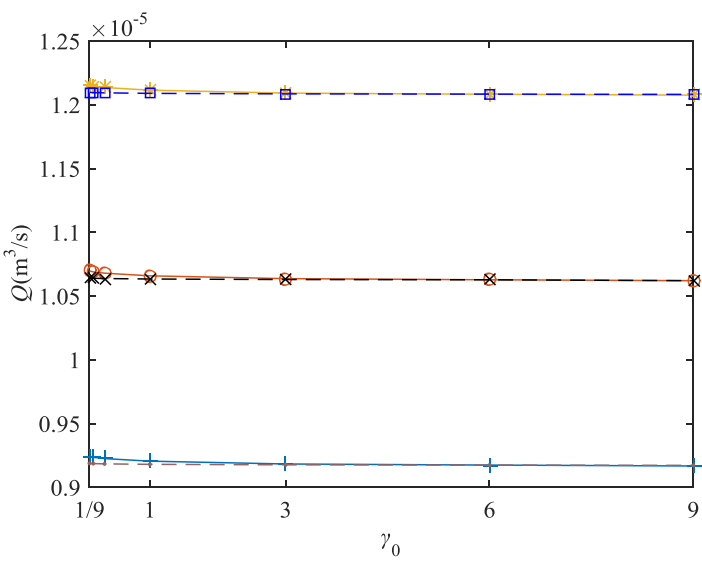

(c) Side leakage flow

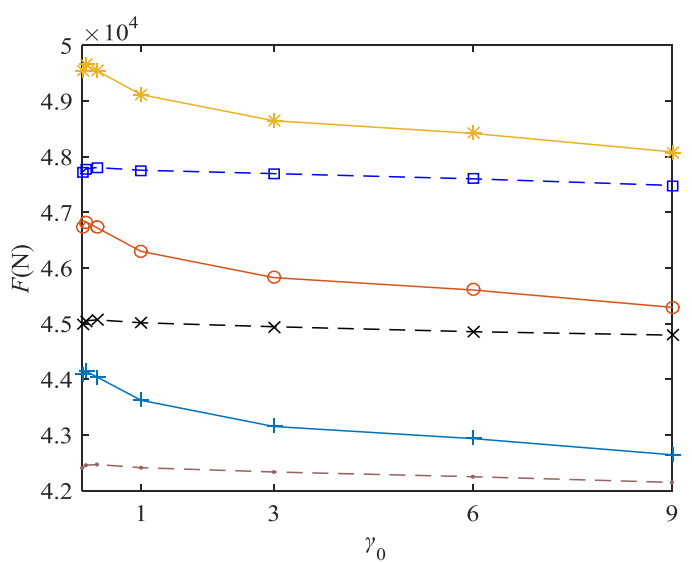

(b) Load-carrying capacity

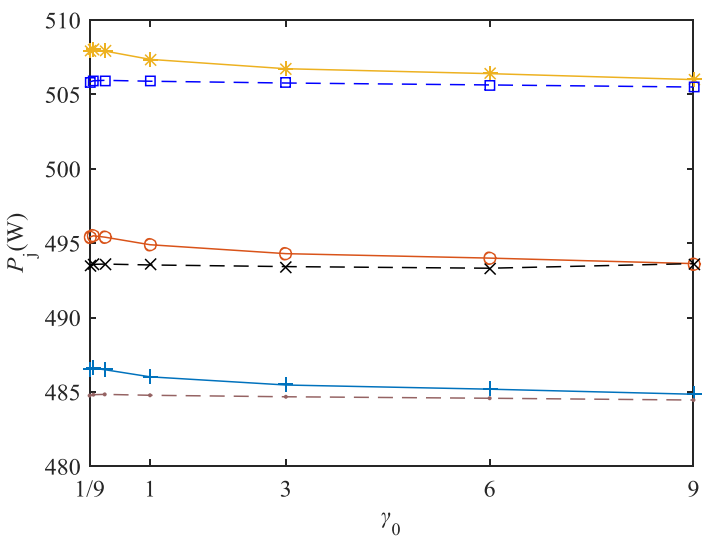

(d) Friction power loss

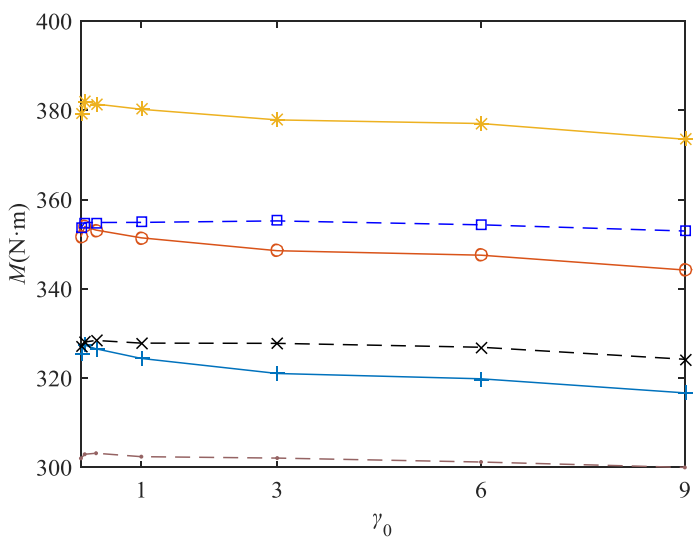

$$
\begin{aligned}
& \perp V=0 \mathrm{~m} / \mathrm{s}, \sigma_{1}=0.4, \sigma_{2}=0.8 \\
& -V=0.5 \mathrm{~m} / \mathrm{s}, \sigma_{1}=0.4, \sigma_{2}=0.8 \\
& \text { * } V=1 \mathrm{~m} / \mathrm{s}, \sigma_{1}=0.4, \sigma_{2}=0.8 \\
& -V=0 \mathrm{~m} / \mathrm{s}, \sigma_{1}=0.2, \sigma_{2}=0.4 \\
& -*-V=0.5 \mathrm{~m} / \mathrm{s}, \sigma_{1}=0.2, \sigma_{2}=0.4 \\
& -\bullet-V=1 \mathrm{~m} / \mathrm{s}, \sigma_{1}=0.2, \sigma_{2}=0.4
\end{aligned}
$$

(e) Overturning moment

Fig. 7. The lubricating characteristics of bearing against the $\gamma$ under different axial velocity $\left(\gamma=0.007^{\circ} ; \varepsilon=0.8 ; n=2500 \mathrm{rpm}\right)$ : (a) maximum oil film pressure; (b) load-carrying capacity; (c) side leakage flow; (d) friction power loss; (e) overturning moment.

is $58.78,63.35$ and $68.71 \mathrm{MPa}$, respectively when considering the surface roughness, which is increased by $11.12,6.88$ and $3.86 \%$, respectively. It might be explained that when the eccentricity is constant, the minimum oil film thickness is constant, the maximum oil film pressure gets significantly increase with the increase of the axial velocity of misaligned journal, thereby the effect of surface roughness is relatively reduced.

\subsection{Influence of surface topography}

Figure 7 shows the variation of the lubrication characteristic parameters of bearing versus the surface pattern parameter $\gamma_{0}$ for three different axial velocity of misaligned journal under different surface roughness of the journal and bearing. It can be seen that when the axial velocity of misaligned journal is constant, with the 
surface change from the transverse roughness pattern to the longitudinal roughness pattern as the value of surface pattern parameter increases, the lubrication characteristic parameters of bearing are reduced to varying degrees. And, the greater the value of surface roughness, the more obvious the change. The reason maybe is that the larger the value of surface roughness, the more the distribution of three-dimensional topography is affected by the surface pattern parameter. As the axial velocity of misaligned journal increases, the influence of surface pattern parameter on the lubrication characteristics of bearing is slightly reduced. The main reason for this phenomenon is that the maximum oil film pressure will increase significantly while considering the axial movement of journal, and the larger the axial velocity of journal, the more significant the increase, which reduces the influence degree of surface pattern parameter. For the surface pattern parameter is $1 / 9$, when the axial velocity of misaligned journal is $0,0.5$ and $1 \mathrm{~m} / \mathrm{s}$, the maximum oil film pressure is $60.69,65.21$ and $70.45 \mathrm{MPa}$ respectively. When the surface pattern parameter is 9, the maximum oil film pressure is 55.81, 60.36 and 65.33 MPa, respectively, which are reduced by $8.06,7.44$ and $7.27 \%$, respectively.

\section{Conclusions}

In this paper, the effect of the axial movement of journal on the performances of journal bearing with rough surface under different misaligned angle, rotational speed and eccentricity is studied. The results are compared to which not consider the axial movement, and the associated conclusions have been drawn:

- regardless of whether the surface roughness is considered, the values of lubrication characteristic parameters of bearing get increase with an increase of the axial velocity of misaligned journal, and the larger the misalignment angle, the more significant the effect of axial velocity;

- compared with not considering the axial movement of misaligned journal, the influence degree of the axial movement on the maximum oil film pressure, loadcarrying capacity and overturning moment of bearing is reduced when considering the surface roughness, and the lower the rotational speed of journal, the more obvious the influence;

- compared with not considering the surface roughness, the impact degree of the surface roughness on the lubrication characteristics of bearing is significantly reduced as the axial velocity of misaligned journal increases;

- when the axial velocity of misaligned journal is constant, the influence of the surface roughness on the maximum oil film pressure, load-carrying capacity and overturning moment of bearing is gradually increased as the increase of eccentricity compared with not considering surface roughness. The smaller the axial velocity, the more significant the influence of surface roughness;

- as the surface changes from the transverse roughness pattern to the longitudinal roughness pattern, the lubrication characteristic parameters of misaligned journal bearing are reduced to varying degrees, and the smaller the axial velocity, the more obvious the change.

\section{Nomenclature}

$c \quad$ Clearance of bearing ( $\mathrm{mm}$ )

$e_{0} \quad$ Eccentricity ratio at the bearing axial midsection

erf () Error function

$F \quad$ Load capacity of journal bearing $(\mathrm{N})$

$F_{U} \quad$ Frictional force caused by circumferential movement of journal (N)

$F_{V} \quad$ Frictional force caused by axial movement of journal $(\mathrm{N})$

$F_{x} \quad$ Load capacity components at $x$ coordinate direction of bearing $(\mathrm{N})$

$F_{z} \quad$ Load capacity components at $z$ coordinate direction of bearing $(\mathrm{N})$

$h \quad$ Oil film thickness $(\mu \mathrm{m})$

$h_{T} \quad$ Local film thickness $(\mu \mathrm{m})$

$k \quad$ Number of iteration

$L \quad$ Bearing width (mm)

$M \quad$ Overturning on the journal bearing $(\mathrm{N} \cdot \mathrm{m})$

$M_{x} \quad$ Overturning moment at $x$ coordinate direction of bearing $(\mathrm{N} \cdot \mathrm{m})$

$M_{z} \quad$ Overturning moment at $z$ coordinate direction of bearing $(\mathrm{N} \cdot \mathrm{m})$

Numbers of grids at circumferential of bearing Rotational speed of journal (rev/min)

Numbers of grids at axial direction of bearing Total friction power loss (W)

Oil film pressure $(\mathrm{MPa})$

Total side leakage flow $\left(\mathrm{m}^{3} / \mathrm{s}\right)$

Lubricant leakage flow from the front-end plane of bearing $\left(\mathrm{m}^{3} / \mathrm{s}\right)$

Lubricant leakage flow from the rear-end plane of bearing $\left(\mathrm{m}^{3} / \mathrm{s}\right)$

$\begin{array}{ll}R & \text { Bearing radius ( } \mathrm{mm}) \\ \Delta t & \text { Time required for the journal to rotate an unit }\end{array}$ angle (s)

$U$ Velocity of the surface of journal at the circumferential direction $(\mathrm{m} / \mathrm{s})$

$V \quad$ Velocity of journal at the direction of bearing axis $(\mathrm{m} / \mathrm{s})$

$x \quad$ Coordinate along the circumferential direction of bearing $(\mu \mathrm{m})$

$y \quad$ Coordinate along the axial direction of bearing ( $\mu \mathrm{m})$

$\alpha \quad$ Angle between $\psi$ and the connecting line between the center of journal $\left(^{\circ}\right)$

Misalignment angle of journal $\left(^{\circ}\right)$

$\gamma$

$\gamma_{0}$

$\psi$

$\theta$

$\sigma_{1}$

$\sigma_{2} \quad$ Surface roughness of bearing $(\mu \mathrm{m})$

$\sigma \quad$ Composite rms roughness

$\eta \quad$ Dynamic viscosity of lubricant $(\mathrm{Pa} \cdot \mathrm{s})$

$\phi_{f p}, \phi_{f}, \phi_{f s}$ Shear stress factors

$\phi_{x}, \phi_{y}, \phi_{s} \quad$ Pressure and shear flow factors 
Acknowledgement. The authors would like to express their gratitude to the Science Fund of State Key Laboratory of Engine Reliability of China (skler-201708) and the National Natural Science Foundation of China $(51490660 / 51490661)$ for the financial support of the research.

\section{References}

[1] J. Sun, C. Gui, Hydrodynamic lubrication analysis of journal bearing considering misalignment caused by shaft deformation, Tribol. Int. 37 (2004) 841-848

[2] J. Sun, C. Gui, Z. Li, An experimental study of journal bearing lubrication effected by journal misalignment as a result of shaft deformation under load, J. Tribol. Trans. ASME 127 (2005) 813-819

[3] J. Sun, M. Deng, Y. Fu, Thermohydrodynamic lubrication analysis of misaligned plain journal bearing with rough surface, J. Tribol. Trans. ASME 132 (2010) 0742-4787

[4] J. Sun, X. Zhu, L. Zhang, Effect of surface roughness, viscosity-pressure relationship and elastic deformation on lubrication performance of misaligned journal bearings, Ind. Lubr. Tribol. 66 (2014) 337-345

[5] Z. Liu, J. Zhou, L. Yu, Computation on pressure distribution of stern bearing liquid film reckoning in inclination of stern shaft, J. Wuhan Univ. Technol. 31 (2009) 111-113

[6] R. Mallya, S. Shenoy, R. Pai, Steady state characteristics of misaligned multiple axial groove water-lubricated journal bearing, Proc. Inst. Mech. Eng. Part J: J. Eng. Tribol. 229 (2014) 712-722

[7] X. Zhang, Z. Yin, D. Jiang, Load carrying capacity of misaligned hydrodynamic water-lubricated plain journal bearings with rigid bush materials, Tribol. Int. 99 (2016) $1-13$

[8] X. Zhang, G. Gao, Z. Yin, Numerical analysis and experimental research on load carrying capacity of waterlubricated tilting-pad thrust bearings, Mech. Ind. 19 (2018) 201-209

[9] Z. He, J. Zhang, W. Xie, Misalignment analysis of journal bearing influenced by asymmetric deflection, based on a simple stepped shaft model, J. Zhejiang Univ. 13 (2012) 647-664

[10] P. Isaksson, D. Nilsson, R. Larsson, The influence of surface roughness on friction in a flexible hybrid bearing, Proc. Inst. Mech. Eng. Part J: J. Eng. Tribol. 225 (2011) 975-985

[11] F. Lv, Z. Rao, T. Na, Mixed-lubrication analysis of thin polymer film overplayed metallic marine stern bearing considering wall slip and journal misalignment, Tribol. Int. 109 (2017) 390-397
[12] F. Lv, Z. Rao, T. Na, Mixed-lubrication analysis of misaligned bearing considering turbulence, Tribol. Int. 119 (2018) 19-26

[13] S. Das, S. Guha, Numerical analysis of steady-state performance of misaligned journal bearings with turbulent effect, J. Braz. Soc. Mech. Sci. 41 (2019) 81

[14] T. Rao, A. Rani, T. Nagarajan, Analysis of journal bearing with double-layer porous lubricant film: Influence of surface porous layer configuration, Tribol. Trans. 56 (2013) 841-847

[15] J. Li, G. Zhang, Y. Huang, Influence of non-gaussiandistributed surface roughness on the static performance of slider bearings, Tribol. Trans. 60 (2016) 739-752

[16] X. Wang, L. Zhou, M. Huang, Numerical investigation of journal misalignment on the static and dynamic characteristics of aerostatic journal bearings, Measurement 128 (2018) 314-324

[17] B. Manser, I. Belaidi, A. Hamrani, Performance of hydrodynamic journal bearing under the combined influence of textured surface and journal misalignment: A numerical survey, C.R. Mec. 347 (2019) 141-165

[18] C. Gui, J. Sun, Z. He, A dynamic solution method for dynamically loaded bearing, Tribol. Trans. 54 (2010) 384393

[19] J. Sun, X. Zhu, L. Zhang, Experimental research on a threedimensional journal orbit of a crankshaft bearing for an internal combustion engine, J. Tribol. Trans. ASME. 136 (2014) 031708

[20] Y. Han, C. Chan, Z. Wang, Effects of shaft axial motion and misalignment on the lubrication performance of journal bearings via a fast mixed EHL computing technology, Tribol. Trans. 58 (2015) 247-259

[21] Y. Han, S. Xiong, J. Wang, A new singularity treatment approach for journal-bearing mixed lubrication modeled by the finite difference method with a herringbone mesh, J. Tribol. Trans. ASME 138 (2016) 011704

[22] N. Patir, H. Cheng, An average flow model for determining effects of three-dimensional roughness on partial hydrodynamic lubrication, J. Lubr. Technol. Trans. ASME 100 (1978) $12-17$

[23] N. Patir, H. Cheng, Application of average flow model to lubrication between rough sliding surfaces, J. Lubr. Technol. Trans. ASME. 101 (1979) 220-230

[24] H. Nakai, N. Ino, H. Hashimoto, Effects of film temperature on piston-ring lubrication for refrigeration compressors considering surface roughness, J. Lubr. Technol. Trans. ASME. 120 (1998) 252-258

[25] Y. Guo, X. Lu, W. Li, A mixed-lubrication model considering elastoplastic contact for a piston ring and application to a ring pack, Proc. Inst. Mech. Eng. Part D: J. Auto. Eng. 229 (2015) 174-188

Cite this article as: B. Li, J. Sun, S. Zhu, Y. Fu, X. Zhao, H. Wang, Q. Teng, Y. Ren, Y. Li, G. Zhu, Effect of the axial movement of misaligned journal on the performance of hydrodynamic lubrication journal bearing with rough surface, Mechanics \& Industry $\mathbf{2 0}$, $402(2019)$ 